07

\title{
Генерация терагерцового излучения в многослойных квантово-каскадных гетероструктурах
}

\author{
(C) А.В. Иконников ${ }^{1,2}$, К.В. Маремьянин ${ }^{1,2}$, C.В. Морозов ${ }^{1,2}$, \\ В.И. Гавриленко ${ }^{1,2}$, А.Ю. Павлов ${ }^{3}$, Н.В. Щаврук ${ }^{3}$, \\ Р.А. Хабибуллин ${ }^{3}$, Р.Р. Резник ${ }^{4,5,6}$, Г.Э. Цырлин ${ }^{4,5,6,7}$, \\ Ф.И. Зубов ${ }^{4}$, А.Е. Жуков ${ }^{4,7}$, Ж.И. Алфрёров ${ }^{4,7}$
}

${ }^{1}$ Институт фризики микроструктур РАН, Нижний Новгород

${ }^{2}$ Нижегородский государственный университет им. Н.И. Лобачевского, Нижний Новгород

${ }^{3}$ Институт сверхвысокочастотной полупроводниковой электроники РАН, Москва

${ }^{4}$ Санкт-Петербургский национальный исследовательский Академический университет РАН

${ }^{5}$ Институт аналитического приборостроения РАН, Санкт-Петербург

${ }^{6}$ Санкт-Петербургский национальный исследовательский университет иноормационных технологий, механики и оптики

${ }^{7}$ Санкт-Петербургский научный центр РАН

E-mail: antikon@ipmras.ru

Поступило в Редакцию 13 декабря 2017 г.

Исследованы вольт-амперные и излучательные характеристики многослойных квантово-каскадных гетероструктур $\mathrm{GaAs} / \mathrm{AlGaAs}$ с двойным металлическим волноводом. Продемонстрированы ВАХ, типичные для квантовых каскадных лазеров. Наблюдался пороговый рост интенсивности и узкий спектр излучения, что характерно для лазерной генерации. Измеренная частота излучения составила около $3 \mathrm{THz}$, что совпадает с расчетным значением. Таким образом, впервые продемонстрированы полностью отечественные квантово-каскадные лазеры THz-диапазона.

DOI: 10.21883/PJTF.2017.07.44473.16602

Квантово-каскадные лазеры (ККЛ) - малогабаритные высокоэффективные полупроводниковые источники излучения, реализованные как в среднем инфракрасном (ИК, 2-24 $\mathrm{m})$, так и в терагерцовом (THz, 60-300 $\mathrm{m}$ ) диапазонах. Идея ККЛ была впервые предложена 
Р.Ф. Казариновым и Р.А. Сурисом в 1971 году [1]. ККЛ представляет собой полупроводниковую гетеросистему с большим (до нескольких сотен) числом туннельно-связанных квантовых ям (КЯ); генерация осуществляется за счет вынужденных переходов электронов между уровнями размерного квантования КЯ [1,2], образующих при приложении внешнего электрического поля усилительный каскад. К настоящему времени реализованы ККЛ, работающие в среднем ИК-диапазоне при комнатной температуре в непрерывном режиме [3] с мощностями, достигающими единиц ватт [4].

Подходы, отработанные при создании ККЛ среднего ИК-диапазона, позволили создать приборы THz-диапазона [5]. Электромагнитные волны этого диапазона отражаются металлами, но проникают через пластмассы, бумагу, сухую древесину и любые мутные среды и мелкодисперсные материалы из-за резкого подавления рэлеевского рассеяния. B THz-диапазоне лежат вращательные спектры многих органических молекул, включая колебания биологически важных коллективных мод ДНК и белков, а также фононные резонансы кристаллических решеток, что позволяет развивать новые методы спектроскопии биологических и полупроводниковых структур. Поскольку энергии фотонов THz-излучения малы, оно не производит ионизации среды и повреждения биомолекул, в отличие, например, от рентгеновского излучения. Это позволяет использовать THz-излучение для медицинской диагностики, в современных системах безопасности, экологического мониторинга, высокоскоростной связи, для контроля качества медикаментов и продуктов питания [6,7]. Все это делает задачу создания компактных, эффективных и дешевых источников излучения THz-диапазона стратегически важной. В то же время в России на данный момент имеются единичные сообщения лишь о создании ККЛ среднего ИК-диапазона $(5-8 \mu \mathrm{m})[8-10]$. Поэтому как создание ТГц ККЛ, так и их всестороннее исследование являются актуальной задачей.

В настоящей работе нами представлены результаты исследований вольт-амперных и спектральных характеристик первых структур ККЛ, полностью изготовленных в России.

Исследуемые структуры были выращены методом молекулярнопучковой эпитаксии на установке Riber 21. За основу была взята конструкция многопериодной гетероструктуры $\mathrm{AlGaAs} / \mathrm{GaAs}$ с тремя КЯ в периоде, описанная в [11] и позволившая получить лазерную генерацию вплоть до $200 \mathrm{~K}$ на частоте $3 \mathrm{THz}$. Рост осуществлялся на 
полуизолирующих подложках GaAs (100). На буферном слое GaAs ocaждался стоп-слой $\mathrm{Al}_{0.8} \mathrm{Ga}_{0.2} \mathrm{As}$ толщиной $200 \mathrm{~nm}$, который в дальнейшем использовался при создании лазерного полоска, а затем выращивалась активная область, состоявшая из 228 периодов, каждый из которых содержит три КЯ GaAs толщиной 8.9, 81.5 и $16 \mathrm{~nm}$, разделенных барьерами $\mathrm{Al}_{0.15} \mathrm{Ga}_{0.85} \mathrm{As}$. Самая широкая КЯ служит экстрактором/инжектором электронов за счет резонансного испускания оптического фонона; она легировалась донорной примесью $(\mathrm{Si})$ с концентрацией $\sim 5 \cdot 10^{16} \mathrm{~cm}^{-3}$. Снизу и сверху активная область была ограничена контактными слоями GaAs: $\mathrm{Si}\left(5 \cdot 10^{18} \mathrm{~cm}^{-3}\right)$ толщиной 75 и $50 \mathrm{~nm}$ соответственно. Более подробно процесс роста структур описан в [12].

Для создания ККЛ в данной работе, как и в [11], была использована схема волновода типа металл-металл, в которой активная область заключается между двумя металлическими слоями. Такой волновод обеспечивает более сильную локализацию поля и меньшие потери по сравнению с плазмонным волноводом [13], хотя такой подход значительно усложняет постростовую обработку структур. Для создания как волноводного ограничения, так и омических контактов была использована металлизация Ti/ $\mathrm{Au}(10 / 500 \mathrm{~nm})$. Выращенную структуру помещали на проводящую подложку-носитель $n^{+}$-GaAs, на поверхность которой были нанесены такие же металлические слои, и сращивали методом термокомпрессионного соединения. Далее производилось последовательное стравливание исходной подложки до стоп-слоя, а затем и самого стоп-слоя, после чего сверху наносилась аналогичная последовательность металлических слоев Тi/Au. В результате структура толщиной около $10 \mu \mathrm{m}$ оказывалась ограниченной двумя металлическими слоями. Далее с использованием электронно-лучевой литографии и сухого травления формировались полоски шириной $100 \mu \mathrm{m}$. Подробное описание процессов формирования волновода дано в [14]. После утонения подложки-носителя до толщины около $100 \mu \mathrm{m}$ выкалывались лазерные чипы длиной около $1.5 \mathrm{~mm}$ (рис. $1, a)$. Какие-либо покрытия или линзы на сколотые грани не наносились. Чипы монтировались на медный теплопровод, являющийся нижним контактом к структуре. К верхнему контакту напаивалась золотая проволока (рис. $1, b$ ).

Исследования вольт-амперных (BAX) и излучательных характеристик полученных структур ККЛ проводились при $T=4.2 \mathrm{~K}$ в импульсном режиме. Структура размещалась во вставке в транспортный гелиевый сосуд Дьюара СТГ-40. Для питания структур использовался 


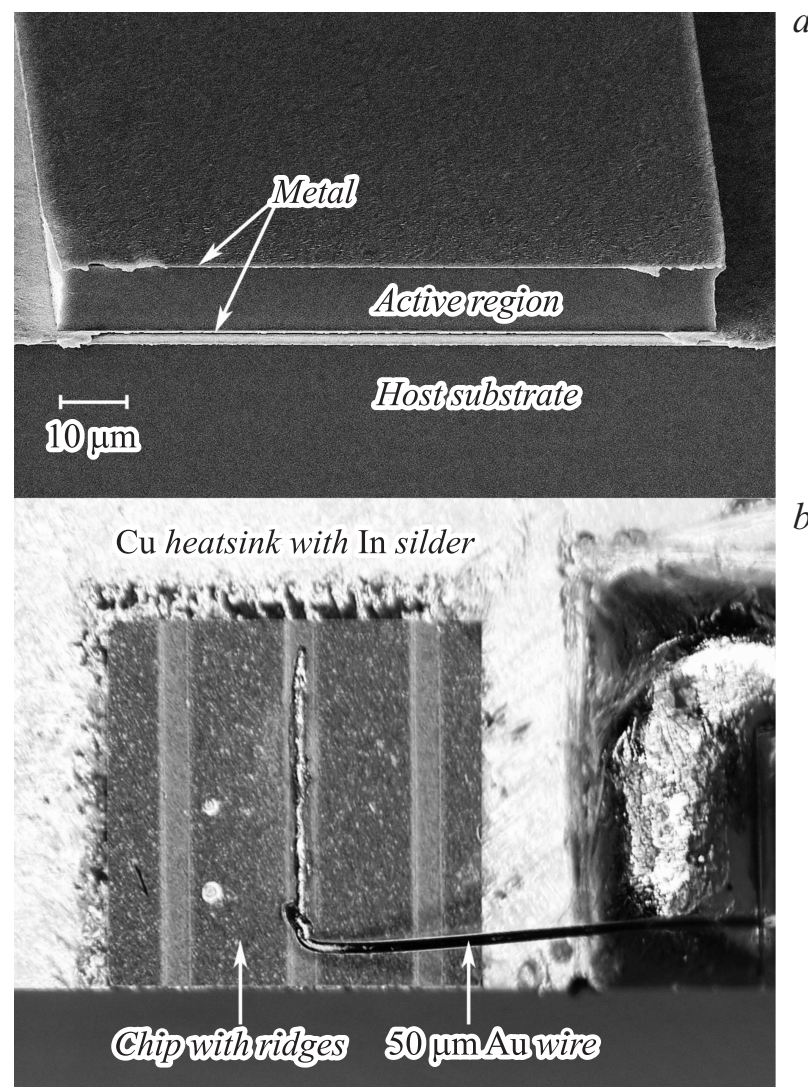

Рис. 1. Микрофотография сколотого торца излучателя $(a)$ и фотография прибора, смонтированного на медном теплоотводе $(b)$.

специально изготовленный электронный ключ на основе полевого транзистора IRF 9510. Задающие прямоугольные импульсы длительностью $10-20 \mu \mathrm{s}$ и частотой повторения $100-1000 \mathrm{~Hz}$ формировались генератором Г5-56. Питание ключа осуществлялось от прибора Keithley 2400 Source Meter, который позволял осуществлять пошаговую развертку выходного напряжения. С выхода ключа импульсы напряжения до $16 \mathrm{~V}$ подавались на исследуемую структуру. При измерени-

Письма в ЖТФ, 2017, том 43, вып. 7 
ях ВАХ сигналы, пропорциональные амплитуде импульсов напряжения и тока, подавались на двухканальный строб-интегратор (boxcar) Stanford Research Systems SR250. Постоянное напряжение с выхода каждого из каналов строб-интегратора оцифровывалось с помощью аналогоцифрового преобразователя и записывалось в память ЭВМ.

При измерениях интегральной интенсивности излучения ККЛ в зависимости от тока терагерцовое излучение детектировалось примесным фотоприемником $\mathrm{Ge}: \mathrm{Ga}$, который также располагался во вставке в СТГ-40 непосредственно рядом с исследуемым образцом. Смещение на приемник подавалось с предусилителя прибора UNIPAN-232B, использовавшегося в данном эксперименте в качестве широкополосного усилителя с полосой $150 \mathrm{kHz}$. Усиленный сигнал с приемника вместе с импульсом, пропорциональным току через лазер, подавались на два канала строб-интегратора. Сигналы с выхода строб-интегратора оцифровывались и записывались в ЭВМ.

Малая интенсивность излучения исследуемых каскадных структур не позволила использовать для изучения его спектральных характеристик фурье-спектрометр (ср. с [15]), поэтому спектральные исследования проводились с использованием перестраиваемого магнитным полем режекторного фильтра на циклотронном резонансе (ЦР). Использовалась криомагнитная вставка в СТГ-40, в которой между ККЛ и приемником располагался сверхпроводящий соленоид, в центре которого (в разрезе световодной трубки из нержавеющей стали диаметром $4 \mathrm{~mm}$, по которой излучение от ККЛ подводилось к фотоприемнику) помещалась гетероструктура с КЯ $\mathrm{HgTe} / \mathrm{Cd}_{0.7} \mathrm{Hg}_{0.3} \mathrm{Te}$ шириной $8 \mathrm{~nm}$ с двумерным электронным газом. Записывалась зависимость сигнала а фотоприемнике (спектр ЦР в геометрии Фарадея) от магнитного поля. В качестве референсного источника излучения использовался квантовокаскадный лазер, изготовленный фирмой Trion Technology, работающий на частоте $2.99 \mathrm{THz}$ [15]. Вследствие сильной непараболичности зоны проводимости циклотронная масса электронов в КЯ $\mathrm{HgTe} / \mathrm{CdHgTe}$ сильно зависит от концентрации [16], поэтому последняя специально контролировалась с помощью измерений магнитосопротивления гетероструктуры по двухконтактной схеме.

На рис. 2 представлены ВАХ и зависимости интенсивности интегрального излучения от тока для исследуемой каскадной структуры. Такие зависимости вполне типичны для схем ККЛ с резонансным испусканием оптического фонона [17-19]. Наличие платоообразных 


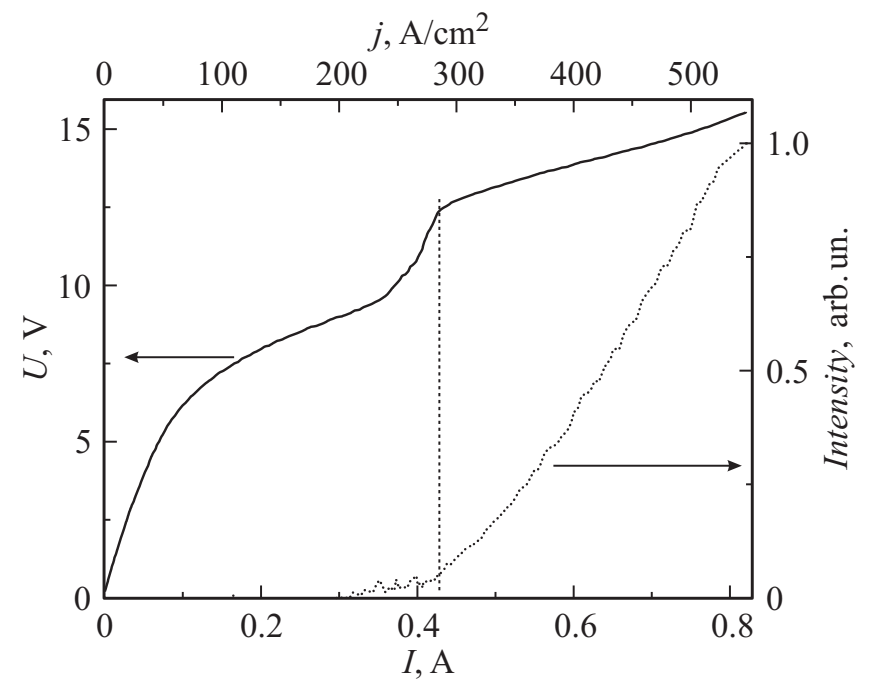

Рис. 2. BAX (сплошная линия) и зависимости интенсивности излучения от тока (точечная линия) исследуемой каскадной структуры.

участков на ВАХ (0.32-0.42 A), скорее всего, связано с образованием доменов электрического поля внутри лазерной структуры. Это подтверждается наличием высокочастотных осцилляций на осциллограммах напряжения и „скачков“ ВАХ в области плато. Подобные домены были подробно исследованы для ККЛ среднего ИК-диапазона [20]. Далее ВАХ претерпевает резкий излом, свидетельствующий о приближении уровня инжектора к верхнему рабочему лазерному уровню, что способствует эффективному туннелированию электронов и быстрому росту тока через структуру. Именно на этом участке в структурах с подобными ВАХ наблюдается возникновение лазерного излучения [17-19]. На зависимости интегральной интенсивности от тока видно (рис. 2), что излом на ВAX при токе $0.42 \mathrm{~A}\left(280 \mathrm{~A} / \mathrm{cm}^{2}\right)$ соответствует началу резкого роста интенсивности излучения, что является признаком возникновения в структуре стимулированного излучения. Кроме того, расчеты, выполненные в работе [21], показывают, что напряжение, соответствующее порогу генерации для данной структуры, составляет около $12.4 \mathrm{~V}$, что совпадает с изломом ВАХ.

Письма в ЖТФ, 2017, том 43, вып. 7 


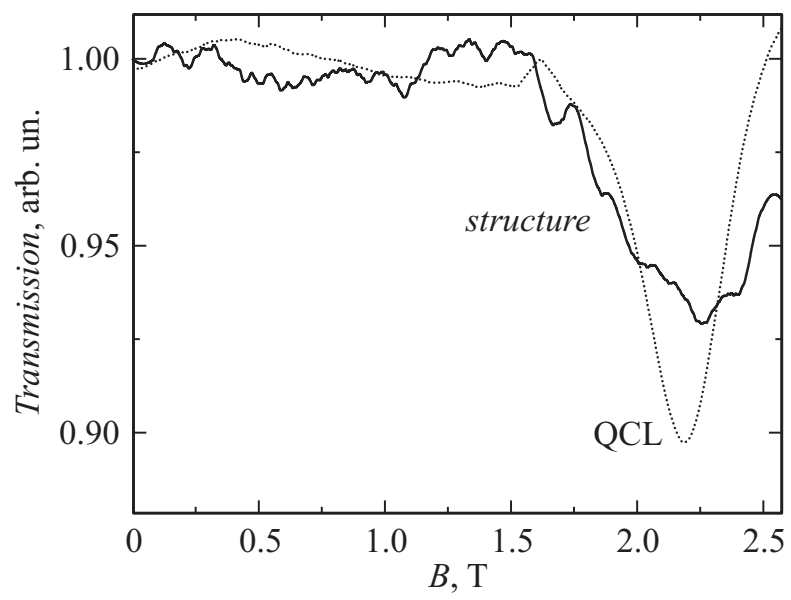

Pис. 3. Спектры циклотронного резонанса в гетероструктуре $\mathrm{HgTe} / \mathrm{Cd}_{0.7} \mathrm{Hg}_{0.3} \mathrm{Te}$ (концентрация электронов $3.7 \cdot 10^{11} \mathrm{~cm}^{-2}$ ), полученные с помощью референсного ККЛ от Trion Technology (точечная линия) и исследуемой каскадной структуры (сплошная линия).

Исследования спектральных характеристик излучения подтверждают предположение о стимулированном характере излучения. На рис. 3 представлены спектры ЦР в гетероструктуре $\mathrm{HgTe} / \mathrm{Cd}_{0.7} \mathrm{Hg}_{0.3} \mathrm{Te}$ (концентрация электронов $3.7 \cdot 10^{11} \mathrm{~cm}^{-2}$ ), полученные как с помощью референсного ККЛ, так и с помощью исследуемой каскадной структуры. При использовании референсного лазера ширина линии ЦР определяется эффективной шириной уровней Ландау в КЯ $\mathrm{HgTe} / \mathrm{CdHgTe}$, а величина поглощения-концентрацией электронов, поскольку лазер можно считать монохроматическим источником излучения. В спектре ЦР, полученного с помощью исследуемой каскадной структуры, линия поглощения чуть смещена в большие магнитные поля по сравнению с линией ЦР, полученной с помощью референсного ККЛ, ее положение соответствует частоте $3.1 \mathrm{THz}$. При этом амплитуда линии поглощения для исследуемой структуры почти такая же, как для референсного ККЛ. Последнее указывает на узкополосность спектра излучения, что является дополнительным свидетельством его стимулированного характера.

Письма в ЖТФ, 2017, том 43, вып. 7 
Таким образом, впервые продемонстрированы полностью изготовленные в России квантово-каскадные лазеры THz-диапазона. Реализован импульсный режим работы ККЛ при температуре жидкого гелия с пороговой плотностью тока около $300 \mathrm{~A} / \mathrm{cm}^{2}$ при напряжении около $13 \mathrm{~V}$. Измеренная частота излучения составляет около $3.1 \mathrm{THz}$, что находится в хорошем согласии с ожидаемым значением $3 \mathrm{THz}$.

Работа выполнена при частичной поддержке Программы фундаментальных исследований Президиума РАН „Наноструктуры: физика, химия, биология, основы технологий,, и гранта Президента РФ № 14.W01.16.6081-MK.

Авторы признательны М. Белкину за полезные обсуждения.

\section{Список литературы}

[1] Казаринов Р.Ф., Сурис Р.А. // ФТП. 1971. Т. 5. В. 4. С. 797-800.

[2] Faist J., Capasso F., Sivco D.L. et al. // Science. 1994. V. 264. P. 553-556.

[3] Beck M., Hofstetter D., Aellen T. et al.// Science. 2002. V. 295. P. 301-305.

[4] Bai Y., Darvish S.R., Slivken S. et al. // Appl. Phys. Lett. 2008. V. 92. P. 101105.

[5] Köhler R., Tredicucci A., Beltram F. et al. // Nature. 2002. V. 417. P. 156-159.

[6] Siegel P.H. // IEEE Trans. Microw. Theory Tech. 2002. V. 50. N 3. P. 910-928.

[7] Chan W.L., Deibel J., Mittleman D.M. // Rep. Prog. Phys. 2007. V. 70. N 8. P. 1325-1379.

[8] Мамутин В.В., Устинов В.М., Boetthcher J., Kuenzel H. // ФТП. 2010. Т. 44. B. 7. С. $995-1001$.

[9] Засавицкий И.И., Зубов А.Н., Андреев А.Ю. и др. // Квантовая электроника. 2016. Т. 46. № 5. С. 447-450.

[10] Бабичев А.B., Bousseksou А., Пихтин Н.А. и др. // ФТП. 2016. Т. 50. В. 10. C. 1320.

[11] Fathololoumi S., Dupont E., Chan C.W.I. et al. // Opt. Express. 2012. V. 20. Iss. 4. P. 3866.

[12] Жуков А.Е., Цырлин Г.Э., Резник Р.Р. и др. // ФТП. 2016. Т. 50. В. 5. С. $674-$ 678.

[13] Williams B.S. // Nat. Photon. 2007. V. 1. P. 517-525.

[14] Хабибуллин Р.А., Щаврук Н.В., Павлов А.Ю. и др. // ФТП. 2016. Т. 50. В. 10. C. $1395-1400$.

[15] Антонов А.В., Гавриленко В.И., Иконников А.В. и др. // Известия вузов. Радиофизика. 2009. T. LII. № 7. Р. 550-556.

Письма в ЖТФ, 2017, том 43, вып. 7 
[16] Ikonnikov A.V., Zholudev M.S., Spirin K.E. et al. // Semicond. Sci. Technol. 2011. V. 26. N 12. P. 125011.

[17] Kumar S., Hu Q., Reno J.L. // Appl. Phys. Lett. 2009. V. 94. P. 131105.

[18] Hu Q., Williams B.S., Kumar S. et al. // Semicond. Sci. Technol. 2005. V. 20. P. S228-S236.

[19] Иконников А.В., Антонов А.В., Ластовкин А.А. и др. // ФТП. 2010. Т. 44. B. 11. C. $1514-1518$.

[20] Lu S.L., Schrottke L., Teitsworth S.W. // Phys. Rev. B. 2006. V. 73. P. 033311.

[21] Хабибуллин Р.А., Щаврук Н.В., Клочков А.Н. и др. // ФТП. 2017. Т. 51. В. 4. C. 540. 